\title{
Batch Adsorption Study of Methylene Blue in Aqueous Solution using Activated Carbons from Rice Husk and Coconut Shell
}

\section{*EDOKPAYI, O; OSEMWENKHAE, O; AYODELE, BV; OSSAI, J; FADILAT, SA; OGBEIDE, SE}

Department of Chemical Engineering, Faculty of Engineering, University of Benin, PMB 1154, Benin City, Edo State, Nigeria. *Corresponding author's Email: edokpayi.osariemen@uniben.edu, bamidele.ayodele@uniben.edu

\begin{abstract}
The removal efficiency of activated carbons prepared from rice husk and coconut shell in the adsorption of methylene blue (azo dye) from the synthetic industrial wastewater was investigated in a batch system. Rice husk and coconut shell were both processed into activated carbon by carbonizing at $600{ }^{\circ} \mathrm{C}$ and activated with $3.0 \mathrm{M} \mathrm{H}_{3} \mathrm{PO}_{4}$ at 80 ${ }^{\circ} \mathrm{C}$ for $3 \mathrm{~h}$. Synthetic solutions of methylene blue were prepared and the adsorption process was carried out by varying initial, methylene blue concentration, adsorbent dosage, and contact. The results showed that higher values of adsorbent dosage and contact time favored the adsorption of methylene blue from the simulated waste water. Activated carbon from coconut shell proved a better adsorbent compared to the activated carbon obtained from rice husk as coconut shell has the highest percentage removal for methylene blue.
\end{abstract}

\section{DOI: https://dx.doi.org/10.4314/jasem.v22i5.4}

Copyright: Copyright (ㅇ 2018 Edokpayi et al. This is an open access article distributed under the Creative Commons Attribution License (CCL), which permits unrestricted use, distribution, and reproduction in any medium, provided the original work is properly cited.

Dates: Received: 0 March 2018; Revised: 13 April: 2018; Accepted: 22 April 2018

Keywords: Activated carbon; Coconut shell; Methylene blue; Rice husk

Synthetic dyes are organic compounds widely used in the textiles, rubber, paper, plastics, cosmetic, and leather industries (Ali et al., 2012; Bhatnagar and Sillanpää, 2010; Yagub et al., 2014). Dye as an organic compounds has the tendency to stick to surfaces of any materials such as fabrics to impact colour (Bouasla et al., 2012). The use of synthetic chemical dyes in for different industrial applications has increased considerably over the years resulting in dye-containing industrial effluent discharged into aquatic ecosystems (Ahmad et al., 2015; Aksu, 2005; Brillas, and Martínez-Huitle, 2015). Due to the recalcitrant and toxic nature of most dyes, discharging them into water bodies often results in environmental pollution (Pagga et al., 1986). The addition of dyes into water bodies often lead to unpleasant colouration of the water surface which usually hinders penetrations of sun lights needed for photochemical and biological activities by the aquatic life (Ertugay and Acar, 2017; Mittal et al., 2014). Hence, it is expedients for the proper treatment of industrial wastewater containing dyes prior to discharging them into water bodies in order abate environmental pollution.

In the past decades, serious research efforts on how to efficiently remove dyes from industrial effluents have resulted in the investigations of methods such as adsorption, advanced oxidation, and membrane separations (Ahmad et al., 2015; Yagup et al., 2014). Reports have shown that these techniques proved to be effective and displayed varying degree of dye removal from the industrial wastewater (Kyzas et al., 2015; Yagub et al., 2015). However, amongst the techniques, adsorption has been established as the most effective with applications in the industries for the removal of recalcitrant pollutants from the effluents prior to discharge into water bodies (Kyzas et al., 2015). Recently, there is a growing attention on the treatment of these dye-containing effluent using cost-effective means by employing activated carbon produced from agriculture waste and industrial as an adsorbent for the removal of these recalcitrants organic compounds (Mohan et al., 2014; Regti et al., 2017). Reports have shown that activated carbon has been obtained from industrial and agricultural waste rich in carbonaceous materials such as nutshells, coconut shell, rice husk, peat, wood, coir, lignite, and coal (Aljeboree et al., 2017; Mullick et al., 2018). This study therefore focuses on the comparative analysis of the performance of activated carbon produced from two industrial waste namely rice husk and coconut shell modified with $\mathrm{H}_{2} \mathrm{PO}_{4}$ used for the adsorption of methylene blue from a synthesized industrial wastewater in a batch system. 


\section{MATERIALS AND METHODS}

Preparation of Activated Carbon: The Rice Husk was obtained from a local milling factory at Niger state, Nigeria. The Coconut Shell was obtained from local coconut candy seller at ring road market, Benin City, Nigeria. The coconut shell and rice husk were initially washed thoroughly with potable water to remove dust, colour, and impurities then rinsed with distilled water and oven dried at $110^{\circ} \mathrm{C}$ for $3 \mathrm{~h}$. Thereafter, both the dried coconut shell and the rise husk were separately grind, carbonated and activated with $\mathrm{H}_{3} \mathrm{PO}_{4}$. The carbonization of the dried rice husk and coconut shell were performed in a muffle furnace. Each of the two sample were kept in crucible and heated separately from ambient temperature to the carbonization temperature of $600{ }^{\circ} \mathrm{C}$ for $1 \mathrm{~h} .200 \mathrm{~g}$ each of the carbonized samples were activated using in $400 \mathrm{ml}$ of $3 \mathrm{M} \mathrm{H}_{3} \mathrm{PO}_{4}$ for $4 \mathrm{~h}$. Thereafter, the mixtures were filtered and the $\mathrm{pH}$ was checked and adjusted to $\mathrm{pH}$. Subsequently, each of the samples were sieved using a $35 \mathrm{mesh}$ sized sieve to obtain a particle size of $0.45 \mathrm{~mm}$ and stored separately in a sealable airtight plastics.

Preparation of Aqueous solution of Methylene Blue: Methylene blue solution of different concentration was prepared by dissolving an appropriate amount of methylene blue in a $1000 \mathrm{ml}$ volumetric flask containing distilled water. The final methylene blue concentration was determined by using absorbance values measured at $668 \mathrm{~nm}$ after the treatment with visible spectrometer (Nwabanne and mordi, 2009).

Batch Experimental Studies: The batch experimental studies were conduction by mixing $100 \mathrm{ml}$ of methylene blue with varying initial concentration and $2 \mathrm{~g}$ of the adsorbent in a set of $250 \mathrm{ml}$ Erlenmeyer flasks (Hameed et al., 2008). The mixture was agitated maintaining a speed of $120 \mathrm{rpm}$ at room temperature. At interval of 20 min, a known solution was taken from the mixture to measure the concentration of the methylene blue.

In order to ensure a clear solution, the sample was initially filtered to remove any activated carbon residues that might interfere with the reading. UV-Vis spectrophotometer was employed to measure the concentration of the methylene blue in the supernatant solution. The amount of methylene blue adsorbed by a unit mass of an adsorbent at equilibrium $\left(\mathrm{Q}_{\mathrm{e}}\right)$, the amount of MB absorbed at any time and the adsorption percentage $(\% \mathrm{R})$ were calculated using the Equations (1)-(3), respectively (Abechi et al, 2011).

$$
Q_{e}=\frac{C_{o}-C_{e}}{m} V
$$

$$
\begin{array}{r}
Q_{t}=\frac{C_{O}-C_{t}}{m} V \\
\text { Percent removal }=\frac{C_{o}-C_{t}}{C_{o}} 100
\end{array}
$$

\section{RESULTS AND DISCUSSION}

Effect of Initial Methylene Blue Concentration: The influence of the initial methylene blue concentration $(50,100,150,200,250,300) \mathrm{mg} / \mathrm{l}$ on the adsorption rate using the adsorbents from rice husk and coconut shell were investiagted. The experiment was carried out using a constant adsorbent dosage of $2 \mathrm{~g}$, at room temperature $\left(26 \pm 1{ }^{\circ} \mathrm{C}\right)$. The effect of the initial methylene blue concentration on its removal efficiency is depicted in Figure 1.

It can be seen that the percentage removal of methylene blue decreases from $38 \%$ to $6 \%$ as the concentration increases from 50 to $300 \mathrm{mg} / \mathrm{l}$. The trends observed for the removal of the methylene blue using adsorbent derived from rice husk revealed that the adsorption of methylene blue at room temperature is favoured at a higher concentration (Hameed et al., 2008). Moreover, the trend observed could be attributed to the fact that increase in concentration increases the number of methylene blue molecules with the limited adsorbent particle to attach to, and therefore the rate at which methylene blue molecule passes from the bulk solution to the adsorbent surface was highly reduced. A similar trend was also observed for the removal of methylene blue using adsorbent obtained from coconut shell. However, the percentage methylene blue removal of coconut shell adsorbent is higher compared to that of rice husk adsorbent because coconut shell is more porous and contain more active sites than rice husk (Aksu, 2005).

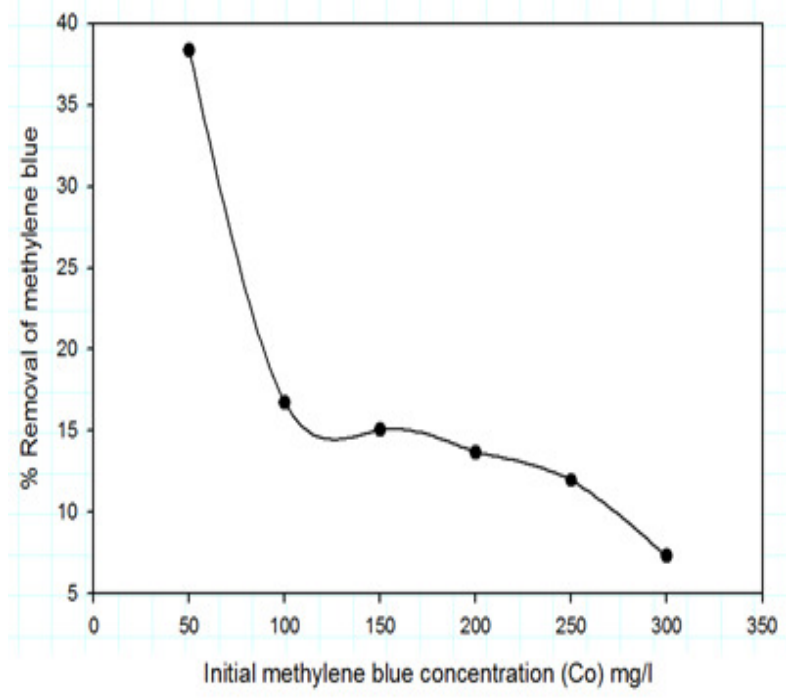

Figure 1. Effect of initial dye concentration on the removal of methylene blue using adsorbents from rice husk. 


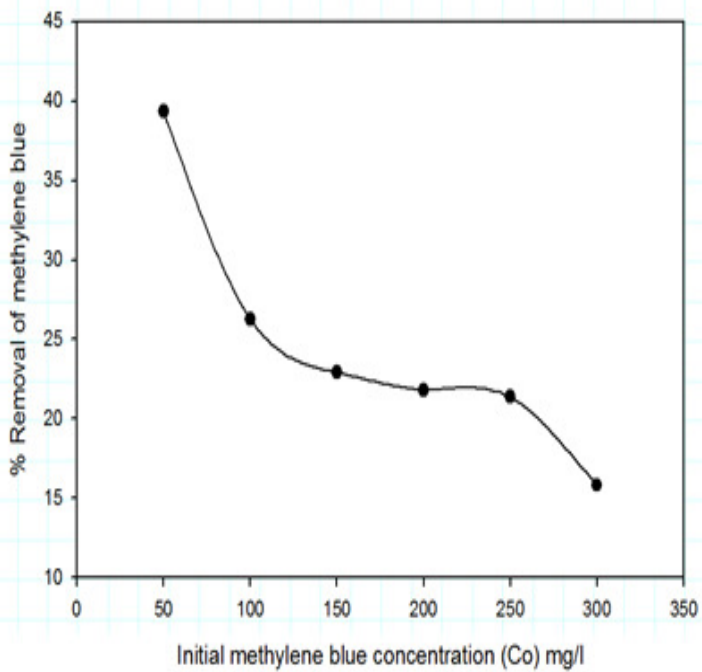

Figure 2. Effect of initial dye concentration on the removal of methylene blue using adsorbents from rice husk.

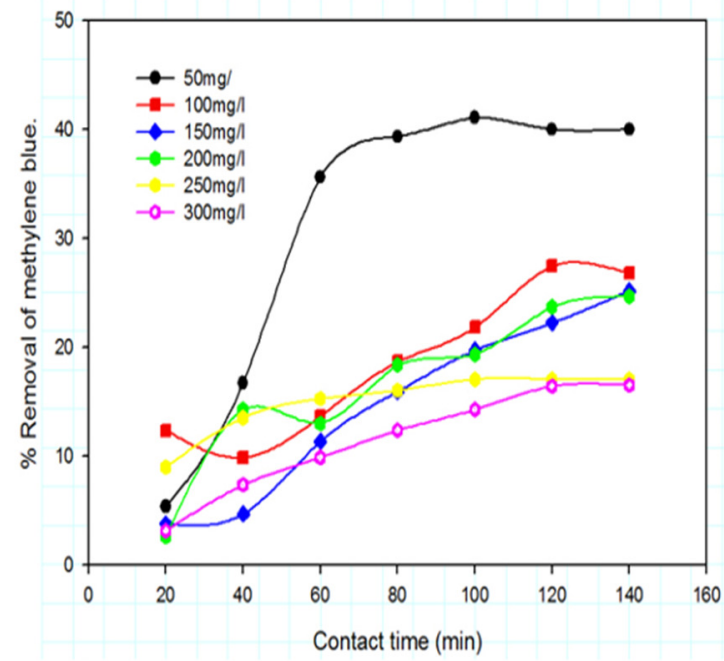

Figure 3: Effect of Contact time and initial methylene concentration on the removal of methylene blue using Coconut shell-based adsorbent.

Effect of Contact Time and Initial Methylene Concentration on the Removal Efficiency of the Methylene blue: The effect of contact time and the initial methylene concentration on the removal efficiency of the methylene blue using the two adsorbents from coconut shell and rice husks are depicted in Figure 3 and 4, respectively. It can be seen that the contact time for agitating the mixture of the adsorbents and the methylene blue solutions at varying initial methylene concentration had significant effect on the removal efficiency of the methylene by the two adsorbents. The increase in the contact time from 20 to $140 \mathrm{~min}$ resulted in corresponding increase in the amount of methylene blue removed from the solution. This could be attributed to the increase rate of mass transfer and molecular diffusion from the bulk solution to the adsorbent (Weng and Pan, 2003). Moreover, the contact time seems to have more impact on the percentage methylene removal at higher initial methylene concentration. The adsorption of methylene blue by rice husk and coconut shell increased steadily throughout the 140 min contact time. The fast kinetics process observed at the initial stage can be attributed to the abundant availability of active binding site on the adsorbent which are later occupied as the process proceeds (Mavi et al., 2004). In the long run it was observe that coconut shell has a better adsorption capacity to rice husk

Effect of Adsorbent Dosage: The effect of the adsorbent dosage $(0.5,1,1.5,2,2.5$, and $3 \mathrm{~g})$ on the percentage removal of methylene blue using rice huskand coconut shell-based adsorbent are depicted in Figures 5 and 6, respectively. The effect of adsorbent dosage on the removal of the methylene blue from the solution was used to investigated to determine the capacity of adsorbent for a given initial adsorbate concentration and binding site available for adsorption. It can be seen that as the adsorbent dosage of the coconut shell-and rice husk-based adsorbent were increased from 0.5 to $3.0 \mathrm{~g}$, there was a corresponding increase in the percentage removal of the methylene blue from the solution. This is an indication that the increase in the adsorbent dosage increases the methylene blue uptake as a result of the increase in the population of active site (Ho et al., 1995). For rice husk and coconut shell the maximum removal of methylene blue was observed at an adsorbent dosage of $3 \mathrm{~g}$.

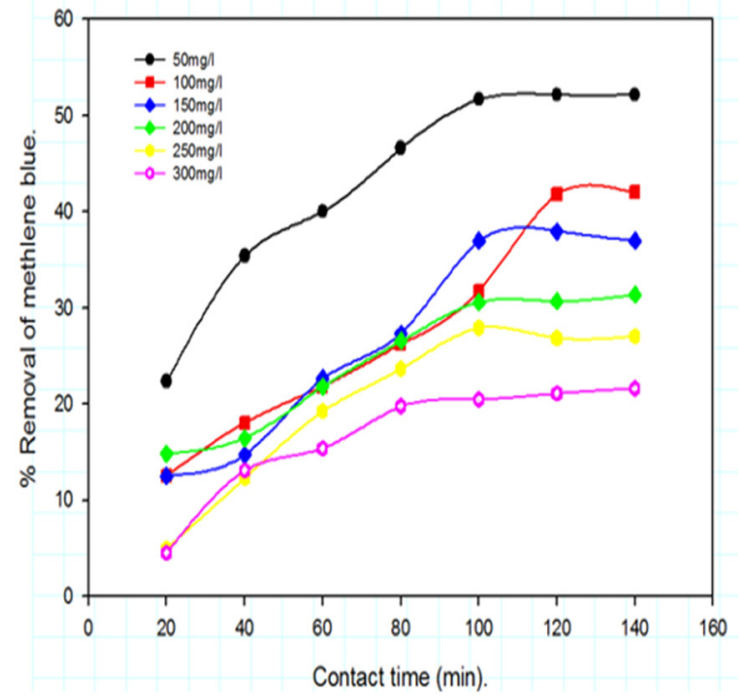

Figure 4: Effect of Contact time and initial methylene concentration on the removal of methylene blue using rice huskbased adsorbent. 


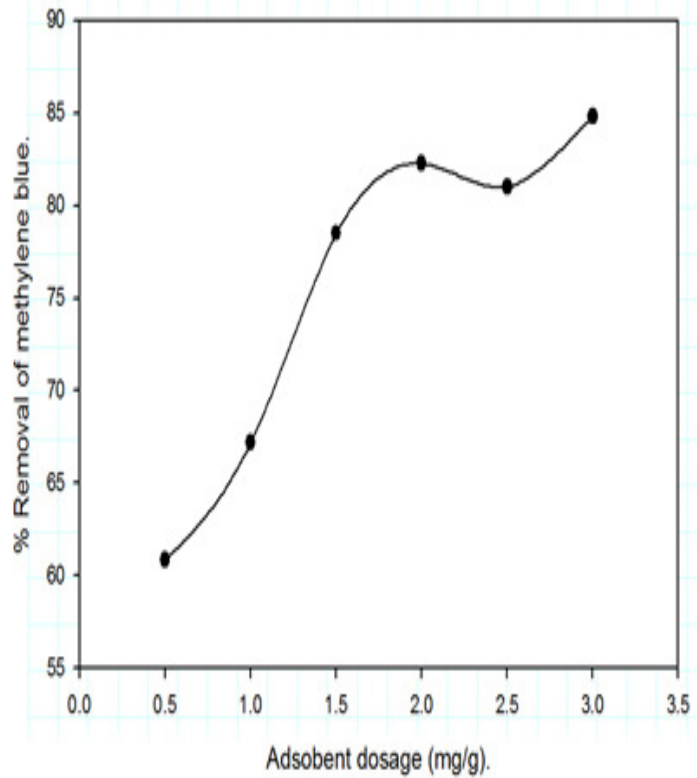

Figure 5: Effect of adsorbent dosage of rice husk on the removal of methylene blue

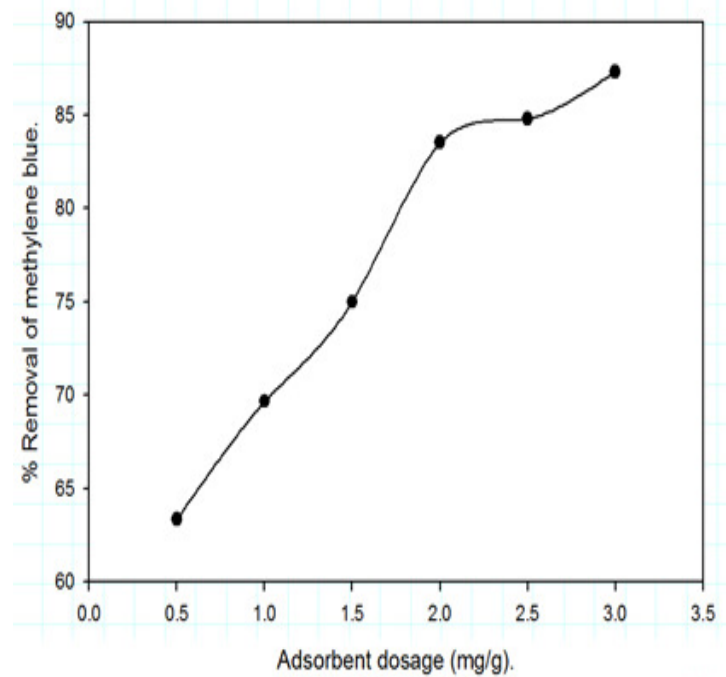

Figure 6: Effect of adsorbent dosage of rice husk on the removal of methylene blue

Conclusion: The present study has investigated the comparative analysis of methylene blue removal from synthetic waste water using adsorbent derived from coconut shell and rice husk. It can be inferred from the study that the parameters investigated significantly influenced the uptake of methylene blue from the simulated waste water on to the adsorbents. In all cases, for both coconut shell-and rice husk-based adsorbent, the percentage removal of the methylene blue from the solution increases with initial methylene concentrations, contact time and the adsorbent dosage. The activated carbon from coconut shell proved a better adsorbent compared to the activated carbon of rice husk.

\section{REFERENCES}

Abechi ES; Gimba, CE; Uzairu, A; Kagbu, JA. (2011). Kinetics of the adsorption of methylene blue onto activated carbon prepared from palm kernel shell. Scholar Research Library, 3(1): 154-164.

Aljeboree, AM; Alshirifi, AN; Alkaim, AF. (2017). Kinetics and equilibrium study for the adsorption of textile dyes on coconut shell activated carbon. Arabian journal of chemistry, 10, S3381S3393.

Ahmad, A; Mohd-Setapar, SH; Chuong, CS; Khatoon, A; Wani, WA; Kumar, R; Rafatullah, M. (2015). Recent advances in new generation dye removal technologies: novel search for approaches to reprocess wastewater. RSC Advances, 5(39), 30801-30818.

Aksu, Z. (2005). Application of Biosorption for the Removal Organic Pollutants: a review process. Biochem, 40, 997-1026.

Ali, I; Asim, M; Khan, TA. (2012). Low cost adsorbents for the removal of organic pollutants from wastewater. Journal of environmental management, 113, 170-183.

Bhatnagar, A; Sillanpää, M. (2010). Utilization of agro-industrial and municipal waste materials as potential adsorbents for water treatment-a review. Chemical engineering journal, 157(2-3), 277-296.

Brillas, E; Martínez-Huitle, CA. (2015). Decontamination of wastewaters containing synthetic organic dyes by electrochemical methods. An updated review. Applied Catalysis B: Environmental, 166, 603-643.

Ertugay, N; Acar, FN. (2017). Removal of COD and color from Direct Blue 71 azo dye wastewater by Fenton's oxidation: Kinetic study. Arabian Journal of Chemistry, 10, S1158-S1163.

Ho, YS; John Wase, DA; Forster, CF. (1995) Batch nickel removal from aqueous solution by sphagnum moss peat. Water Research, 29 (5); 1327-1332.

Kyzas, GZ; Siafaka, PI; Pavlidou, EG; Chrissafis, KJ; Bikiaris, DN. (2015). Synthesis and adsorption application of succinyl-grafted chitosan for the simultaneous removal of zinc and cationic dye from binary hazardous mixtures. Chemical Engineering Journal, 259, 438-448. 
Lagergren, S. (1898) About the Theory of So-Called Adsorption of Soluble Substance. Kungliga Svenska Vetenskapsakademiens Handlingar, 24, 1-39.

Mavi, A; Terzi, Z; Ozgen, U; Yildirim, A; Coskun, M. Antioxidant properties of some medical plants: prangos ferulacea (Apiaceae), sedum sempervivoides (crassulaceae), malva neglecta (malvaceae), Cruciata taurica (Rubiaceae), Rosa pimpinefolia (rosaceae), Galium ver subps. Varum (Rubiaceae). Boil. pharm. Bull. 27(5), 702-705.

Mittal, A; Thakur, V; Mittal, J; Vardhan, H. (2014). Process development for the removal of hazardous anionic azo dye Congo red from wastewater by using hen feather as potential adsorbent. Desalination and Water Treatment, 52(1-3), 227-237.

Mohan, D; Sarswat, A; Ok, YS; Pittman Jr, CU. (2014). Organic and inorganic contaminants removal from water with biochar, a renewable, low cost and sustainable adsorbent-a critical review. Bioresource technology, 160, 191-202.

Mullick, A; Moulik, S; Bhattacharjee, S. (2018). Removal of Hexavalent Chromium from Aqueous Solutions by Low-Cost Rice Husk-Based
Activated Carbon: Kinetic and Thermodynamic Studies. Indian Chemical Engineer, 60(1), 58-71.

Nwabanne, JT; Mordi MI., (2009). Equilibrium uptake and sorption dynamics for the removal of a basic dye using bamboo. African Journal of Biotechnology, 8 (8): 1555-1559.

Olgun, AN; Atar, (2009). Equilibrium and kinetic adsorption study of Basic Yellow 28 and Basic Red 46 by a boron industry waste. Journal of Hazardous Materials, 161, 148-156.

Pagga, U; Brown, D. (1986). The degradation of dye stuffs. Chemosphere. 15, 479-491.

Regti, A; Laamari, MR; Stiriba, SE; El Haddad, M. (2017). Potential use of activated carbon derived from Persea species under alkaline conditions for removing cationic dye from wastewaters. Journal of the Association of Arab Universities for Basic and Applied Sciences, 24, 10-18.

Weng, CH; Pan, YF. (2006). Adsorption characteristics of methylene blue from aqueous solution by sludge ash, Colloids Surf. A: Physicochem. Eng. Aspects 274, 154-162.

Yagub, MT; Sen, TK; Afroze, S; Ang, HM. (2014). Dye and its removal from aqueous solution by adsorption: a review. Advances in colloid and interface science, 209, 172-184. 